\title{
Article \\ Using a Modified VIKOR Technique for Evaluating and Improving the National Healthcare System Quality
}

\author{
Sun-Weng Huang ${ }^{1,2}{ }^{\oplus}$, James J. H. Liou ${ }^{1, *(D)}$, Hai-Hua Chuang ${ }^{3,4}{ }^{\oplus}$ and Gwo-Hshiung Tzeng ${ }^{2}$ \\ 1 Department of Industrial Engineering and Management, National Taipei University of Technology, \\ Taipei 10608, Taiwan; t107379004@ntut.org.tw \\ 2 Graduate Institute of Urban Planning, College of Public Affairs, National Taipei University, \\ New Taipei City 23741, Taiwan; ghtzeng@gm.ntpu.edu.tw \\ 3 Department of Family Medicine, Chang-Gung Memorial Hospital, Taipei \& Linkou Branch, \\ Taoyuan 33305, Taiwan; chhaihua@gmail.com \\ 4 College of Medicine, Chang Gung University, Taoyuan 33302, Taiwan \\ * Correspondence: jamesjhliou@gmail.com; Tel.: +88-(62)-771-2171 (ext. 2332)
}

Citation: Huang, S.-W.; Liou, J.J.H.; Chuang, H.-H.; Tzeng, G.-H. Using a Modified VIKOR Technique for Evaluating and Improving the National Healthcare System Quality. Mathematics 2021, 9, 1349. https:// doi.org/10.3390/math9121349

Academic Editors: Victoria López and Laureano González Vega

Received: 25 May 2021

Accepted: 7 June 2021

Published: 11 June 2021

Publisher's Note: MDPI stays neutral with regard to jurisdictional claims in published maps and institutional affiliations.

Copyright: () 2021 by the authors. Licensee MDPI, Basel, Switzerland. This article is an open access article distributed under the terms and conditions of the Creative Commons Attribution (CC BY) license (https:// creativecommons.org/licenses/by/ $4.0 /)$.

\begin{abstract}
The effectiveness of the national/regional healthcare system is one of the keys to prevent the spread of COVID-19. In the face of this unknown pandemic, where the healthcare system should continue to be promoted and improved are crucial decision issues. In the past, most studies have used the subjective opinions of experts for analysis and decision-making processes when investigating complicated decision-making problems. However, such decision-making processes are easily influenced by experts' preferences. Therefore, this research proposes a soft computing technology that integrates CRiteria Importance Through Intercriteria Correlation (CRITIC) with the modified VlseKriterijumska Optimizacija I Kompromisno Resenje in Serbian, meaning multicriteria optimization and compromise solution (modified VIKOR) technique to reduce the impact of expert preference. In order to cope with the fact that COVID-19 has spread globally and to discover problems quickly and effectively, this study uses the global health security (GHS) index as the evaluation framework and conducts overall discussions in 195 countries/regions around the world. It is verified that the technology of soft computing can be used for continuous promotion and improvement of the national/regional healthcare system. This technology facilitates decision makers to know the gap of performance between the current healthcare system and the aspiration level. Finally, based on these gaps, we provide management advice to help improve these systems.
\end{abstract}

Keywords: COVID-19 epidemic; healthcare system quality; modified VIKOR technique; hybrid multiple attribute decision-making (MADM) method; anti-epidemic

\section{Introduction}

Over the past 20 years, the effects of various viral diseases on humans have been documented, including the severe acute respiratory syndrome coronavirus (SARS-CoV) outbreak of 2002-2003, and the H1N1 influenza in 2009. In 2012, the Middle East respiratory syndrome coronavirus (MERS-CoV) was discovered for the first time in Saudi Arabia. However, the impact of the current COVID-19 pandemic has challenged humanity's recent advances in epidemic prevention. The World Health Organization has classified COVID-19 as a major worldwide pandemic, posing a serious threat to humanity as it has spread around the world. For example, Fernandes [1] showed that the pandemic's continued spread will likely cause severe damage to the world economy, estimating that every additional month of the crisis could cause a 2.5-3\% reduction in the global GDP. Consequently, how to quickly and effectively fight the epidemic is a critical decision for the countries affected.

Most efforts have focused on the development of treatments and a vaccination to fight the virus [2-4]. Chinese researchers were the first to propose a non-medical solution, specifically the strategy of quarantine to control the spread of the infection [5-7]. Requia et al. [8] 
posited that a functional national healthcare system is an important fundamental to fight the epidemic. Many studies have shown that increasing the basic capacity and quality of the national health facilities is important in the fight against COVID-19, directly impacting the ability to control the infection and having some influence on the safety of the whole country [8-10]. In other words, enhancing the national healthcare system has a big impact on ensuring a country's competitive advantage and sustainability.

Today, in the face of the continued spread of the pandemic across the globe, the management of the national healthcare system has become extremely important. Factors commonly used to evaluate the quality of a national healthcare system have been detailed in past studies such as the global health observatory indicators (GHOS), Organization for Economic Co-Operation and Development (OCED), International Quality Indicators Project (IQIP), Agency for Healthcare Research and Quality (AHRQ), and Healthcare Quality Indicator Project (HCQI) [11-15]. Some researchers have also used the number of hospital beds, composite measures (medical workers and ICU beds), and medical care spending as direct measures of the quality of bedside medical care $[16,17]$. It should be noted that some of these indicators are normally used to measure the quality of medical care within medical institutions, and some to measure quality on both the institutional and regional level. In addition, there are some indicators that are specifically used to measure the quality of an international healthcare system. Although the existing evaluation frameworks are all quite complete, and the areas they can be used to evaluate are quite wide, and using them to conduct a thorough evaluation often requires a complex process and a large amount of time. Other measures that can be taken into consideration include healthcare capacity, healthcare management, healthcare accessibility, interdisciplinary communication, infection control, and the difficulty of adopting new technology [18-20]. This study proposes the six measures mentioned above to quickly assess the current state of a national healthcare system during the current severe epidemic [19].

In the past, traditional analysis and the multiple criteria decision method (MCDM) have been used to analyze the healthcare system. However, questions remain related to the indicator weight settings (most of which are analyzed by the subjective weights of experts) and how to improve value in the former method [18], while the latter method usually employs collective rankings for a comparison of the selected alternatives or solutions. In real-world management problems, it is often necessary to perform a collective evaluation using a limited number of methods, and then choose the most suitable solution from among a limited number of solutions. It is also often the case that this solution is most effective only in a given area, whereas in reality, decision makers need to understand the gap between the aspiration levels and actual performance in all areas, and then minimize this gap. The traditional MCDM is not suitable to find the rankings of these gaps, being designed to find the best solution among the various solutions, rather than comparing the difference between the real and the aspiration levels.

This study uses soft computation methods, namely the CRiteria Importance Through Intercriteria Correlation (CRITIC) and modified VlseKriterijumska Optimizacija I Kompromisno Resenje in Serbian, meaning multicriteria optimization and compromise solution (modified VIKOR) methods, to evaluate the national healthcare system. First, CRITIC is used to calculate the objective weights of all the related criteria for evaluating the national healthcare system (this differs from the expert weights used in the past). CRITIC can efficiently differentiate the characteristics of the individual criteria by examining their relative strengths, using the relations between them to evaluate criteria weights [21,22]. Then, a modified VIKOR method is used to analyze the medical and health systems of those countries in the world demonstrating superior epidemic prevention performance. The gap between the current performance level of the national medical and healthcare system and the desired level is confirmed, so that each country can clearly know how to achieve better results. This method can effectively remedy the limitations of the past evaluation methods by avoiding the dilemma of having to "select good apples from among the rotten apples" $[23,24]$. 
The results of this study can provide a comprehensive scientific method to help countries affected by the epidemic to identify problems with their national healthcare systems, with results that are closer to real needs. The contributions are as follows: First, a soft computing method is employed to quickly and accurately determine the priority rankings of the evaluation criteria, combined with a modified VIKOR method to allow countries that are already performing well to understand what aspects can be improved further, and to achieve the aspiration goals to improve upon already good performance. Second, the latest statistics obtained from an open database are used to quickly determine directions for improvement in the face of the spread of infection, and to propose strategies to improve the healthcare system.

The remainder of the paper is structured as follows: Section 2 presents a systematic review of past literature on healthcare system assessment. An introduction of the basic concepts of soft computing is given in Section 3, and a case study and discussion are presented in Section 4. Finally, the conclusion and directions for future research are presented in Section 5.

\section{Healthcare System}

The methods used for healthcare system evaluation in past studies can be roughly divided into three types, namely qualitative, quantitative, and hybrid methods [25-27]. From the perspective of knowledge management, Karltun et al. [26] used a qualitative approach to explore the improvement of healthcare system quality. Based on a combination of semi-structured interviews and non-participant observations, they found that national healthcare policies, hospital management, and medical professionals all affect the improvement of quality. Budiwan [25] conducted an in-depth survey of 15 patients and recorded, transcribed, and then analyzed the contents of their responses. They found that, from the perspective of patients, technical, interpersonal, tangibles, and access, as well as responsiveness, value, and outcomes, are all important criteria for evaluating the quality of a healthcare service. Such qualitative methods can be helpful in clarifying the causes of problems, but they lack data and evaluation support.

Other studies have focused on the use of quantitative methods. There are various different methods used for quantitative analysis, including statistical models, economic models, multi-objective planning, optimization, etc. In a 2020 study of the Polish healthcare system, Zawisza et al. [28] assessed the overall satisfaction of elderly patients and used probability regression models for overall analysis. The results showed that doctorpatient communication skills played an important role in improving patient satisfaction. They emphasized the necessity of overcoming social and psychological problems in the doctor-patient relationship. Numerous previous research studies have employed partial least squares structural equation modeling (PLS-SEM) to examine the National Health Service in Spain $[29,30]$. One of the studies argued that resource allocation, expenditures, safety, and life expectancy have positive effects on patient satisfaction. Furthermore, Valls Martínez et al. [30] investigated health investment management and healthcare quality from a gender perspective and concluded that females are more sensitive about the public health investment than males; meanwhile, the expenditure level directly influenced patient satisfaction of both males and females. Based on the abovementioned findings, the following statements could be drawn. Firstly, PLS-SEM could be regarded as one of the proper methods to investigate healthcare system issues. Secondly, patient satisfaction could be considered as one of the crucial influencing factors of the hygiene system. In recent years, continuous innovations in science and technology, especially the growth of artificial intelligence and the development of chatbots, have led to changes that are affecting the healthcare system. These technologies can be applied to improve the effectiveness of the healthcare system. Artificial intelligence and chatbots are dependent on calculation technology and decision-making technology [31]. Many recent studies have focused on these technological breakthroughs and applications. For example, Chen et al. [32]. believe that, due to the multi-modality of medical data, traditional machine learning and data-mining 
methods cannot accurately discover the hidden value in the data, that edge computing technology should thus be used to carry out more comprehensive analysis, and that the power of science and technology can be applied to improve the healthcare system.

The multivariate linear models, because of their reliability, have been widely used to propose improvement strategies and to increase the efficiency of healthcare logistics. Hejazi et al. [33] used this method to perform analysis with stress-strength reliability as a control variable (i.e., number of beds in the medical facility). Others have argued that price-based strategies are a more effective method for improving the healthcare system. These strategies employ multi-objective planning mathematical methods. It has been found that using a new contract policy, it is possible to achieve higher quality medical service with shorter waiting times [34]. Likewise, Teymourifar et al. [34] used multi-objective analysis models and a combination of strategies to perform an evaluation of a healthcare system from the perspective of patient spending and develop strategies for improvement. Their results show that the proposed strategies can achieve effective improvements and create a better medical system.

Many studies favor using data envelopment analysis (DEA), combining the concepts of input and output with different techniques for healthcare analysis. For example, Yaya et al. [35] used weighted DEA along with a hybrid game theory model to develop a method for the improvement of healthcare system quality and management. Unlike the traditional DEA models, their decision-making unit-based method uses k-means and a canopy algorithm to group homogeneous units into a single group, then performs an evaluation on each individual group. The results of analysis by quantitative models are supported by data. However, gathering data can be difficult and time consuming, and the accuracy is uncertain. This has led to the development of hybrid quantitative and qualitative methods to improve the solutions. The various MCDM methods that are representative of this strategy can simultaneously consider quantitative and qualitative variables in the analysis process [36-38]. In a review of over 200 papers focusing on healthcare analysis and healthcare problems, Mardani et al. [36] found that the analytic hierarchy process (AHP) and fuzzy AHP were the most commonly used decision-making techniques.

Otay et al. [39] used a mixed model to evaluate the efficiency of medical institutions. Their model, based on DEA, combined with AHP, and intuitionistic fuzzy sets (IFS), can be used to find the rankings in an uncertain environment. In addition, others have addressed the issue from the perspective of sustainability to establish a mixed sustainability-resilience framework with the goal of ultimately raising the quality, efficiency, and effectiveness of medical and healthcare services. The analysis was based primarily on DEA combined with the best-worst method (BWM), as well as the use of advantage-weakness-opportunitythreat (AWOT) analysis to provide appropriate suggestions [40]. Si et al. [41] used a decision-making trial and evaluation laboratory (DEMATEL)-based model to establish key performance indicators (KPI) for the healthcare system. That method uses interval 2-tuple linguistic variables to consider the semantics problems of the decision-makers. Others have integrated interval type-2 fuzzy sets (IT2FSs) with simulation methods to improve hospital room stay performance. This method combines the interval type-2 fuzzy AHP (IT2FAHP) and elimination and choice translating reality (ELECTRE) techniques, and the simulation results showed that the average length of stay (LOS) can be improved [42]. Amiri et al. [43] employed a new model for the evaluation of hospital performance. Their model is based on BWM fuzzy preference programming for the integration of the opinions of different experts. Integrated cross-domain models have been proposed for quality control of the healthcare system. Such models first use confirmatory factor analysis to confirm the variables affecting quality control, then apply the VIKOR grey relational analysis (VIKOR-GRA) to find the importance rankings of the influential factors, and finally the importance-performance analysis (IPA) technique to perform correction [38].

Tuzkaya et al. [44] carried out an overall assessment of the quality of medical service based on patient satisfaction. They proposed the interval-valued intuitionistic fuzzy preference ranking organization method for enrichment of evaluations (IVIF-PROMETHEE), 
a method that can be used for medical service quality assessment, which considers the hesitation of patients in the decision-making process. Chang [45] studied the assessment of hospital service quality, believing that the expectations regarding service quality are greatly affected by subjective observations. Their results show that the five most important criteria for assessing hospital service quality are as follows: medical staff with professional capabilities, service staff with the capacity to quickly solve problems, the quality and cleanliness of the bedding, professionally competent and trustworthy medical staff, and the doctors' ability to provide detailed descriptions of the patients' conditions. Based on a similar concept, Baki and Peker [46] established a comprehensive fuzzy evaluation model of hospital service quality. Their model combined the fuzzy AHP and fuzzy technique for order preference by similarity to an ideal solution (TOPSIS) techniques. The empirical results showed that, from the perspective of hospital service quality, "reliability" is the most important standard, while "empathy" is the least important one. In many past studies on healthcare assessment, the concept of ambiguity has been taken into account to assess and choose between different medical institutions [47-49]. From the perspective of efficiency and consistency, it is even more important to perform analysis of the benchmarks. An integrated model has been proposed for this type of analysis, which uses ELECTRE III to rank the evaluated medical institutions, followed by IPA to find the best institution [37].

While all the methods discussed above are effective, they suffer from two limitations. First, most of these methods still require expert opinions for determining criteria weights. Many studies have focused on the problems of linguistic expression, indecision, integrating the opinions of different experts, etc., related to the reliance upon expert opinions $[39,43,45]$. Although these methods have attempted to address the uncertainty of expert opinions, the problem of subjectivity remains. The CRITIC technique can be used to overcome the limitation of needing to rely on expert opinions to support the decision-making system, and to establish accurate criteria rankings using the relationships between criteria. The objective weights are obtainable based on actual performance. In addition, the criteria for evaluating healthcare systems often have complex and conflicting characteristics, and are often closely related, making the CRITIC technique very useful in this area.

Secondly, past performance assessment methods have often been limited to setting the benchmark from the existing alternatives or solutions [37,45]. However, if comparisons are only made with this benchmark, and the number of alternatives to be compared is limited, the evaluation results can very easily fall into the regional best solution. However, in the real world, the concept of the aspiration exists [23,24]. Therefore, using the aspiration level as the basis for analysis, we can work towards these goals, to find the best solution. Among the many performance analysis techniques, the modified VIKOR is a suitable tool to fix the problem analyzed in this study.

\section{Soft Computing Technology}

This section describes in detail the characteristics and calculation steps of the proposed soft computing method. This soft computing method comprises both CRITIC and modified VIKOR models. The CRITIC model is used to determine the weights of the evaluation indicators (criteria), while the modified VIKOR model is used for evaluation and improvement of national healthcare systems. The complete process can be divided into three stages (see Figure 1):

(1) Data collection (definition/normalization);

(2) Application of the CRITIC model to get the objective weights;

(3) Using the modified VIKOR model to evaluate each alternative. 


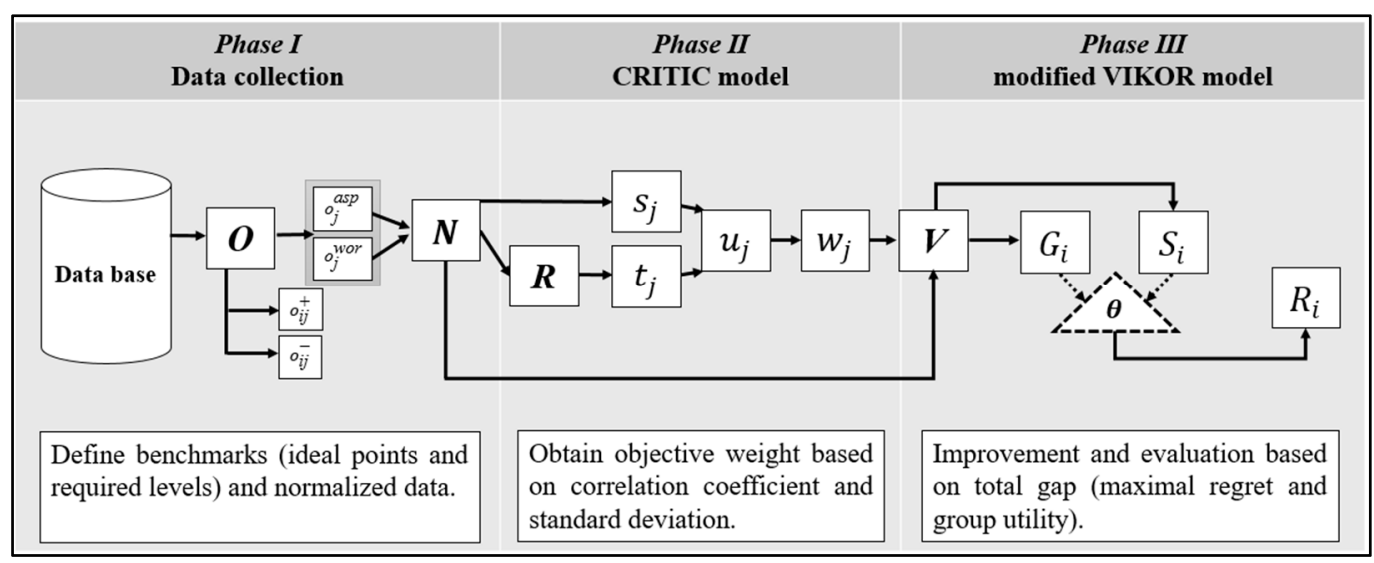

Figure 1. Soft computing analysis process.

\subsection{Phase I: Collection and Collation of Data}

Step 1. Establish an evaluation decision matrix.

Extract performance data from the database to obtain a performance evaluation matrix $O$, where $A_{i}$ is alternative $i$ and $D_{j}$ is criterion $j$. Therefore, the $o_{i j}$ stands for the performance of $i$ alternatives in criterion $j$.

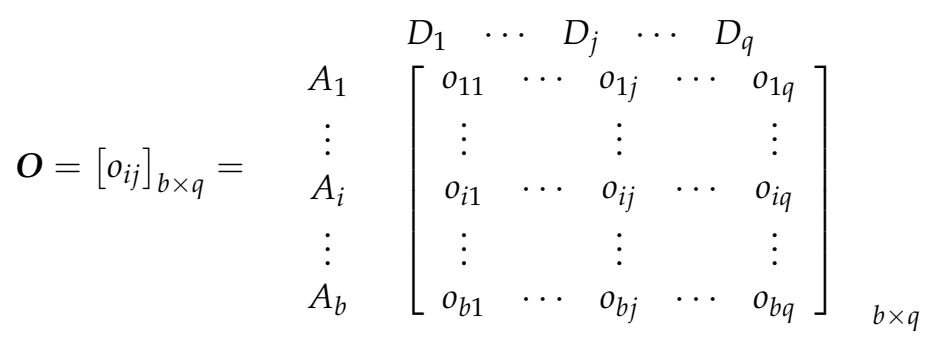

Step 2. Set the values of the benchmark.

First, define the ideal point. Ideal points are divided into positive and negative, where the positive ideal point has the maximum value and the negative ideal point has the minimum value.

$$
\begin{aligned}
& o_{i j}{ }^{+}=\max _{i}\left\{o_{i j} \mid i=1,2, \cdots, b\right\}, j=1,2, \cdots, q, \\
& o_{i j}{ }^{-}=\min _{i}\left\{o_{i j} \mid i=1,2, \cdots, b\right\}, j=1,2, \cdots, q .
\end{aligned}
$$

Next, define the goals as the aspiration level and acceptable level, with the aspiration level being the highest and the tolerance level the lowest.

$$
\begin{gathered}
o_{j}^{a s p}=100=\left(o_{1}^{a s p}, \cdots, o_{j}^{a s p}, \cdots, o_{q}^{a s p}\right), \\
o_{j}{ }^{\text {woor }}=0=\left(o_{1}{ }^{\text {wor }}, \cdots, o_{j}^{\text {woor }}, \cdots, o_{q}{ }^{\text {wor }}\right) .
\end{gathered}
$$

Using performance on a 0 to 100 scale as an example, ranging from very poor/ unsatisfactory $\leftarrow 0,1,2, \ldots, 99,100 \rightarrow$ very good/satisfactory. Using this scale in an intuitive linguistic survey, the aspiration level would be set at 100 and the tolerance level as 0 . Thus, the aspiration level in our study $=100$, and the tolerance level $=0$. This aspect is different from the traditional max-min method.

Step 3. Get the normalized matrix $N$.

Use Equation (2) to normalize the performance measures and get the normalized matrix $N$, as shown in Equation (3).

$$
n_{i j}=\left|o_{j}^{a s p}-o_{i j}\right| /\left|o_{j}^{a s p}-o_{j}^{w o r}\right|
$$




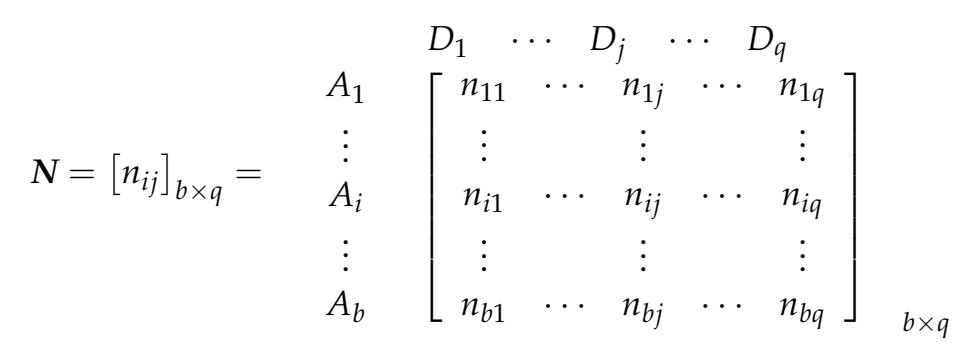

\subsection{Phase II: Derive the Objective Weights}

Step 1. Calculate the standard deviation of each criterion.

Based on the normalized matrix $N$, calculate the average values and standard gaps of all criteria, as shown in Equations (4) and (5).

$$
\begin{aligned}
s_{j}=\sqrt{s^{2}} & =\sqrt{\sum_{i=1}^{b}\left(n_{i j}-\bar{n}\right)^{2} / b} \text { for } j=1,2, \ldots, q \\
\bar{n}_{j} & =\frac{\left(n_{1 j}+\cdots+n_{i j}+\cdots+n_{b j}\right)}{b}
\end{aligned}
$$

Step 2. Calculate the correlation coefficient between the two criteria.

Use the normalized matrix $N$ to calculate the relationships between the criteria, and the correlation coefficients, as shown in Equation (6), where $r_{k j}$ is the correlation coefficient between the $k$ th and $k$ th criteria.

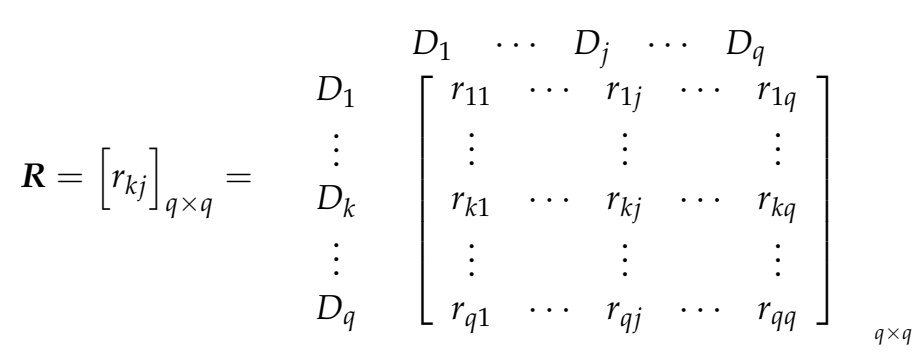

Step 3. Calculate the weights of each criterion.

Calculate the deviation and standard gaps of each criterion. Based on the deviation and standard gaps of all criteria we can obtain the final objective weights, as shown in Equations (7)-(9).

$$
\begin{gathered}
t_{j}=\sum_{k=1}^{q}\left(1-r_{k j}\right) \\
u_{j}=s_{j} \sum_{k=1}^{q}\left(1-r_{k j}\right) \\
w_{j}=u_{j} / \sum_{k=1}^{q} u_{k}
\end{gathered}
$$

\subsection{Phase III: Use the Modified VIKOR to Perform the Evaluation}

The traditional VIKOR and modified VIKOR method are developed as an Lp-metric.

$$
L_{p, i}=\left\{\sum_{j=1}^{b}\left[w_{j}\left(p_{j}^{*}-p_{i j}\right) /\left(p_{j}^{*}-p_{j}^{-}\right)\right]^{p}\right\}^{1 / p}, 1 \leq p \leq \infty ; i=1,2, \cdots, b .
$$


Within the VIKOR method, the solution obtained considers both the maximum group utility (majority rule, shown as the average gap,) and the minimum individual regret (shown as the lowest performance between guidelines).

In the traditional VIKOR method the ideal point is used as the benchmark, whereas the modified VIKOR uses the aspiration level as the goal to propose the final weightings, as shown in Figure 2.

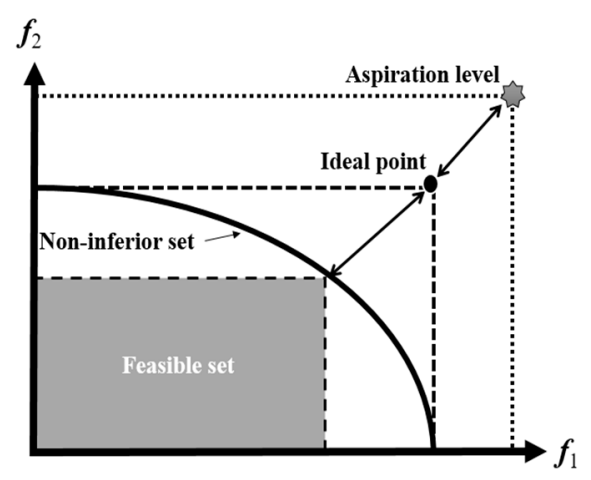

Figure 2. Compromise solutions for the ideal point and aspiration level.

Step 1. Calculate the maximal regret $S_{i}$ and mean of the group utility $G_{i}$. Obtain the maximal gap and calculation average gap, as shown in Equations (10) and (11).

$$
\begin{gathered}
S_{i}=\max _{j}\left(n_{i j}\right)=\max _{j}\left(\left|o_{j}^{a s p}-o_{i j}\right| /\left|o_{j}^{a s p}-o_{j}^{w o r}\right| \mid j=1,2, \ldots, q\right) \\
G_{i}=\sum_{j=1}^{n} w_{j} n_{i j}=\sum_{j=1}^{n} w_{j}\left(\left|o_{j}^{a s p}-o_{i j}\right| /\left|o_{j}^{a s p}-o_{j}^{w o r}\right|\right)
\end{gathered}
$$

Step 2. Compute the value.

Use strategy coefficients to calculate the total gap $R_{i}$. The strategy coefficient is set according to the degree of dependence on the mean of the group utility and maximal regret, where $G^{a s p}=L^{a s p}=0, G^{\text {wor }}=L^{\text {wor }}=1$, as shown in Equation (12). The $\theta$ is a coefficient adjusted according to different situations. In this study, the default value is 0.5 . This means that both distances are equally important.

$$
R_{i}=\theta \times \frac{G_{i}-G^{a s p}}{\left(G^{w o r}-G^{a s p}\right)}+(1-\theta) \times \frac{S_{i}-S^{a s p}}{\left(S^{w o r}-S^{a s p}\right)}
$$

\section{Empirical Example}

COVID-19 has become a worldwide pandemic. An epidemic prevention system is the most important defense for protecting each country's public health. However, with the rapid spread of infection, how each government can quickly and effectively respond to changes in the situation has become a subject of international concern. For this reason, how to quickly and effectively assess a nation's healthcare system is an important issue. The global health security (GHS) index has proven to be an important assessment indicator for controlling the spread of COVID-19 [19].

This index is a new tool suitable for evaluating the health safety of a nation based on original data. Both quantitative and qualitative data are used to indicate the current state of healthcare in 195 countries and regions around the world. Although it is a reliable database, the GHS index still has many problems, for example, derivation of the criteria weights and how to add additional use value [18]. A more objective assessment technique is still needed to make reasonable corrections. Therefore, this study proposes a soft computation method, which can achieve fast and objective analysis of the performance of the healthcare system. 


\subsection{Healthcare System Evaluation Framework}

There have been many studies discussing standards for the evaluation of the healthcare system from various perspectives. However, COVID-19 has proven to be a challenge that humanity has been unable to fully grasp. The rapid transformation of circumstances in the face of constant challenges and shocks has forced changes in the quality and usability of the healthcare system. Therefore, this study proposes a soft computing method designed to perform an objective assessment of the healthcare system in the fastest and most convenient way possible. Data for this study were obtained from the global database of the GHS index [20]. Wong et al. [19] confirmed that the GHS index is an important indicator to control the COVID-19 pandemic. Compared to other databases, GHS index updates are quicker, timelier, and the collection process is comprehensive [18]. To cope with the rapidly changing COVID-19 outbreak, having access to the most recent and up-to-date data is essential. After performing the analysis, six indicators were selected from the GHS including the following: healthcare capacity, healthcare management, healthcare accessibility, interdisciplinary communication, infection control, and difficulty of adopting new technology (Table 1).

Table 1. Indicators for healthcare system evaluation.

\begin{tabular}{ccc}
\hline Code & Indicators & Explanations \\
\hline$D_{1}$ & Healthcare capacity & $\begin{array}{c}\text { Health capacity in clinics, hospitals, } \\
\text { and community care centers }\end{array}$ \\
\hline$D_{2}$ & Healthcare management & $\begin{array}{c}\text { Medical countermeasures and } \\
\text { personnel deployment }\end{array}$ \\
\hline$D_{3}$ & Healthcare accessibility & Healthcare access \\
\hline$D_{4}$ & $\begin{array}{c}\text { Interdisciplinary } \\
\text { communication }\end{array}$ & $\begin{array}{c}\text { Communications with healthcare } \\
\text { workers during a public health } \\
\text { emergency }\end{array}$ \\
\hline$D_{5}$ & Infection control & $\begin{array}{c}\text { Infection control practices and } \\
\text { availability of equipment }\end{array}$ \\
\hline$D_{6}$ & Difficulty of adopting new & Capacity to test and approve new \\
technology & medical countermeasures \\
\hline
\end{tabular}

Healthcare capacity refers to the capabilities of the local clinics, hospitals, and municipal caregiving centers; healthcare management is the readiness of local healthcare policies and personnel; healthcare accessibility is the overall assessment of an area's healthcare coverage, out-of-pocket health expenditures per capita, skilled birth attendants, and prioritization of healthcare services to healthcare workers; interdisciplinary communication indicates the communications with healthcare workers during a public health emergency; infection control refers to the area's healthcare-associated infection (HCAI) monitoring and personal protective equipment (PPE) supply capacity; difficulty of adopting new technology refers to that area's acceptance of new medical technologies.

\subsection{Data Collection}

The GHS index is a project of the Nuclear Threat Initiative (NTI) and the Johns Hopkins Center for Health Security (JHU) and was developed in cooperation with The Economist Intelligence Unit (EIU). To ensure the timeliness of the data, this study used data gathered from the global database of the GHS index [50]. The scale of the data ranged between 0 and 100 , and the larger the value of the index, the better the performance, as shown in Table 2. Data taken from the database included both qualitative and quantitative variables. Data for qualitative variables were taken from governments' public data collection, so they have a certain degree of trustworthiness. Although quantitative data provide a more objective assessment, these qualitative data are effective for filling in information that cannot easily be found in the database. The GHS index assesses the healthcare system according to 
six measures. Survey data are gathered from 195 regions. For each region's performance and original data, the reader can refer to the GHS index website. Examples of the data are shown in Table 2 below.

Table 2. Region-based performance from the database.

\begin{tabular}{cccccccc}
\hline \multirow{2}{*}{ Code } & \multirow{2}{*}{ Region/Country } & \multicolumn{7}{c}{ Indicators } \\
\cline { 3 - 8 } & & $\boldsymbol{D}_{\mathbf{1}}$ & $\boldsymbol{D}_{\mathbf{2}}$ & $\boldsymbol{D}_{\mathbf{3}}$ & $\boldsymbol{D}_{\mathbf{4}}$ & $\boldsymbol{D}_{\mathbf{5}}$ & $\boldsymbol{D}_{\mathbf{6}}$ \\
\hline$A_{1}$ & Argentina & 46 & 66.7 & 48.2 & 50 & 50 & 75 \\
$\vdots$ & Australia & 66.3 & 33.3 & 43.8 & 100 & 50 & 100 \\
$\vdots$ & $\vdots$ & $\vdots$ & $\vdots$ & $\vdots$ & $\vdots$ & $\vdots$ & $\vdots$ \\
$\vdots$ & Belgium & 51.8 & 66.7 & 44.6 & 100 & 50 & 50 \\
$\vdots$ & Brazil & 55.6 & 33.3 & 44.3 & 0 & 50 & 100 \\
$\vdots$ & $\vdots$ & $\vdots$ & $\vdots$ & $\vdots$ & $\vdots$ & $\vdots$ & $\vdots$ \\
$A_{195}$ & Zimbabwe & 3.9 & 33.3 & 29 & 0 & 0 & 25 \\
\hline Note: Database from the GHS index [50]. & & & & & &
\end{tabular}

The performance measures after normalization are shown in Table 3. The step for normalization was formulated as in Equation (2). This step also means we had to perform a process to deal with the units between the six criteria. The elements of all six criteria are between $0-1$, with a smaller value indicating a smaller gap, and a larger value representing a greater distance to the aspiration level, meaning this country's performance is lower in this indicator. To save space, we recorded the detailed data in the raw data Excel file included with this paper. Table 3 shows examples from the normalized performance matrix.

Table 3. Normalized performance matrix.

\begin{tabular}{cccccccc}
\hline \multirow{2}{*}{ Code } & \multirow{2}{*}{ Region/Country } & \multicolumn{7}{c}{ Indicators } \\
\cline { 3 - 8 } & & $\boldsymbol{D}_{\mathbf{1}}$ & $\boldsymbol{D}_{\mathbf{2}}$ & $\boldsymbol{D}_{\mathbf{3}}$ & $\boldsymbol{D}_{\mathbf{4}}$ & $\boldsymbol{D}_{\mathbf{5}}$ & $\boldsymbol{D}_{\mathbf{6}}$ \\
\hline$A_{1}$ & Argentina & 0.540 & 0.333 & 0.518 & 0.500 & 0.500 & 0.250 \\
$\vdots$ & Australia & 0.337 & 0.667 & 0.562 & 0.000 & 0.500 & 0.000 \\
$\vdots$ & Belgium & 0.482 & 0.333 & 0.554 & 0.000 & 0.500 & 0.500 \\
$\vdots$ & Brazil & 0.444 & 0.667 & 0.557 & 1.000 & 0.500 & 0.000 \\
$A_{195}$ & Zimbabwe & 0.961 & 0.667 & 0.710 & 1.000 & 1.000 & 0.750 \\
\hline
\end{tabular}

\section{Analysis Results and Discussions}

In this section, we analyze examples according to the computation steps from the previous section. First, the objective weights of the six measures are described. Second, a soft computation technique is used to assess the healthcare systems of 195 regions around the world. Third, the difference between traditional and modified VIKOR is considered, and finally, we discuss the results of the soft computation technique.

\subsection{Obtain Objective Weights}

The proposed soft computation technique is combined with CRITIC operations and treats the entire world as one system to confirm the objective weights of the criteria. The objective weights are obtained based on the correlation coefficient and standard deviation, as in Equations (4)-(10). Based on Table 3 and using the method outlined in Phase II in Section 3, we first performed analysis using the proposed soft computing method CRITIC to calculate the relationships between the indicators. Table 4 shows the relationships between the six indicators. It can be found that there was a stronger correlation between $D_{1}, D_{2}$, and $D_{6}$ with correlations of $0.539,0.584$, and 0.562 , respectively. Similarly, there was 
a stronger correlation between $D_{5}$ and $D_{6}$ with a correlation of 0.578 . In other words, there is a strong relationship between the three variables (i.e., healthcare capacity, healthcare management, and infection control). Similarly, there is a strong relationship between the two variables of infection control and difficulty of adopting new technology.

Table 4. Correlation matrix of criteria.

\begin{tabular}{ccccccc}
\hline $\boldsymbol{R}$ & $\boldsymbol{D}_{\mathbf{1}}$ & $\boldsymbol{D}_{\mathbf{2}}$ & $\boldsymbol{D}_{\mathbf{3}}$ & $\boldsymbol{D}_{\mathbf{4}}$ & $\boldsymbol{D}_{\mathbf{5}}$ & $\boldsymbol{D}_{\mathbf{6}}$ \\
\hline$D_{1}$ & 1 & 0.539 & 0.337 & 0.340 & 0.584 & 0.562 \\
$D_{2}$ & 0.539 & 1 & 0.327 & 0.290 & 0.453 & 0.451 \\
$D_{3}$ & 0.337 & 0.327 & 1 & 0.165 & 0.303 & 0.415 \\
$D_{4}$ & 0.340 & 0.290 & 0.165 & 1 & 0.358 & 0.385 \\
$D_{5}$ & 0.584 & 0.453 & 0.303 & 0.358 & 1 & 0.578 \\
$D_{6}$ & 0.562 & 0.451 & 0.415 & 0.385 & 0.578 & 1 \\
\hline
\end{tabular}

The standard deviations of each of the six evaluation criteria are shown in Table 5. The weights calculated for the six indicators using CRITIC were $D_{4}>D_{6}>D_{5}>D_{2}>D_{1}>D_{3}$. We can see that the final criterion weights depend upon the gaps and the standard deviation. The three highest weighted indicators were $D_{4}$ (interdisciplinary communication, 0.255 ), $D_{6}$ (difficulty of adopting new technology, 0.180 ), and $D_{5}$ (infection control, 0.175 ). This shows that interdisciplinary communication, difficulty of adopting new technology, and infection control are important measures for evaluating the national healthcare system. Accurate criteria weights are very important in multi-criteria decision evaluation problems. Past methods usually used expert opinions or assumed the weights to be identical, in order to perform a general assessment. This study uses objective weights to perform the final evaluation. This is different from past evaluation methods, and makes the evaluation results more convenient, accurate, and fast, while at the same time it allows us to avoid the problem of individual bias present in the expert judgements.

Table 5. Standard deviation and weights of indicators.

\begin{tabular}{ccccccc}
\hline Coefficient & $\boldsymbol{D}_{\mathbf{1}}$ & $\boldsymbol{D}_{\mathbf{2}}$ & $\boldsymbol{D}_{\mathbf{3}}$ & $\boldsymbol{D}_{\mathbf{4}}$ & $\boldsymbol{D}_{\mathbf{5}}$ & $\boldsymbol{D}_{\mathbf{6}}$ \\
\hline$s_{j}$ & 0.198 & 0.233 & 0.128 & 0.311 & 0.272 & 0.293 \\
$t_{j}$ & 2.638 & 2.939 & 3.453 & 3.463 & 2.724 & 2.609 \\
$u_{j}$ & 0.522 & 0.686 & 0.442 & 1.078 & 0.741 & 0.764 \\
$w_{j}$ & 0.123 & 0.162 & 0.104 & 0.255 & 0.175 & 0.180 \\
\hline
\end{tabular}

\subsection{Soft Computing Evaluation of Healthcare Systems}

Using the proposed soft computing technique, we can obtain the rankings of the healthcare systems for 195 regions. The complete rankings are as shown in the Appendix A Tables A1 and A2. To save space, we used the top 10 ranked subjects as an example for explanation and discussion, as shown in Figure 3. On the right side of the figure, the coefficients of group benefits and individual regrets are drawn as a schematic diagram. This diagram allows us to easily tell the differences in performance in each region, based on group benefits and individual regrets. The green star in the top right corner of the figure represents the aspiration level of the healthcare system performance. The left side of the figure shows the gap from the aspiration level for the 10 regions. It can be seen that the Netherlands, which had the highest ranking, still had a total gap of 0.407 to the aspiration level (green bar); the second one, Canada had a gap of 0.414 ; France, in third place, had a gap of 0.442; Belgium, in fourth place, had a gap of 0.452; the United Kingdom, which is ranked fifth, had a gap of 0.461 . This trend continues for the other regions. These results show that the Netherlands' healthcare system is already performing well in comparison to other countries. However, it still has room for improvement. This example shows that the new computation technique combined with modified VIKOR achieves analysis results that are much more accurate and effective, and closer to the requirements of the real 
world. The proposed soft computing technique not only has the functions of the traditional performance evaluation models (i.e., ranking), but can also provide decision makers with more managerial suggestions regarding how each region can work to raise the standards of its healthcare system in order to achieve the goal of continued improvement. We include a more detailed explanation in the following sections.

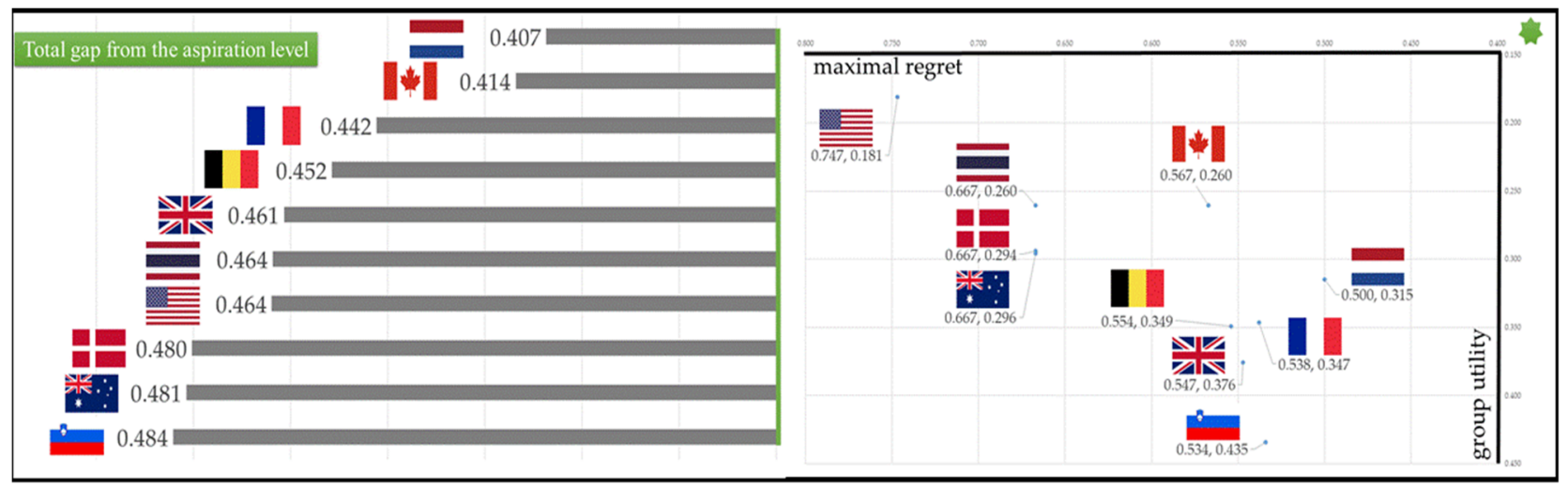

Figure 3. Soft computing evaluation of healthcare systems.

\subsection{Comparison of Modified VIKOR with Traditional VIKOR and Other Methods}

The biggest difference between traditional and modified VIKOR methods lies in the process for determining the benchmark, as in Phase 1, Step 2. The setting of the benchmark results in a major change to the evaluation results. We list the top 10 rankings according to the soft computation results as shown in Table 6 . The left side of Table 6 shows the results obtained with the traditional model.

Table 6. Comparison of new and traditional soft computing results.

\begin{tabular}{ccccccccc}
\hline \multirow{2}{*}{ TOP 10 } & \multicolumn{3}{c}{ Traditional VIKOR } & \multicolumn{3}{c}{ Modified VIKOR } \\
\cline { 2 - 8 } & Region/Country & $\boldsymbol{R}_{\boldsymbol{i}}$ & $\boldsymbol{S}_{\boldsymbol{i}}$ & $\boldsymbol{G}_{\boldsymbol{i}}$ & Region/Country & $\boldsymbol{R}_{\boldsymbol{i}}$ & $\boldsymbol{S}_{\boldsymbol{i}}$ & $\boldsymbol{G}_{\boldsymbol{i}}$ \\
\hline 1 & Netherlands & 0.078 & 0.500 & 0.290 & Netherlands & 0.407 & 0.500 & 0.315 \\
2 & Canada & 0.101 & 0.550 & 0.244 & Canada & 0.414 & 0.567 & 0.260 \\
3 & France & 0.135 & 0.535 & 0.327 & France & 0.442 & 0.538 & 0.347 \\
4 & Belgium & 0.153 & 0.551 & 0.330 & Belgium & 0.452 & 0.554 & 0.349 \\
5 & United Kingdom & 0.160 & 0.544 & 0.354 & United Kingdom & 0.461 & 0.547 & 0.376 \\
6 & Argentina & 0.169 & 0.515 & 0.417 & Thailand & 0.464 & 0.667 & 0.260 \\
7 & Slovenia & 0.175 & 0.521 & 0.417 & United States & 0.464 & 0.747 & 0.181 \\
8 & South Korea & 0.193 & 0.562 & 0.379 & Denmark & 0.480 & 0.667 & 0.294 \\
9 & Thailand & 0.217 & 0.667 & 0.242 & Australia & 0.481 & 0.667 & 0.296 \\
10 & Denmark & 0.233 & 0.667 & 0.269 & Slovenia & 0.484 & 0.534 & 0.435 \\
\hline
\end{tabular}

The best performance was achieved by the Netherlands (0.078), followed by Canada (0.101), France (0.135), Belgium (0.153), the United Kingdom (0.160), Argentina (0.169), Slovenia (0.175), South Korea (0.193), Thailand (0.217), and Denmark (0.233). The right side shows the results obtained with the modified model. Here the best performance was achieved by the Netherlands (0.407), followed by Canada (0.414), France (0.442), Belgium (0.452), the United Kingdom (0.461), Thailand (0.464), the United States (0.464), Denmark (0.480), Australia (0.481), and Slovenia (0.484).

It is worth noting that when the modified VIKOR is used for calculation, setting the aspiration level makes the changes of all variables much more apparent. We found that the rankings after the sixth changed, as shown in Table 6. The United States, Australia, and Slovenia are now ranked among the top 10 countries; Thailand and Denmark's rankings are higher, and Slovenia's ranking is reduced. 
This new soft computation method based on the traditional VIKOR method, incorporates the aspiration level and worst level into the analysis. Due to the incorporation of the concept of the aspiration level, this analysis method can achieve the goal of finding the best possible solution to pursue in the real world and avoids the problem of having to choose the best solution from among many inferior solutions [24].

Table 7 shows the final results of the proposed soft calculation and the comparison with other methods. The top three alternatives ranked by the modified VIKOR method were: the Netherlands, Canada, and France. The top three alternatives ranked by TOPSIS were: Vanuatu, Japan, and Uzbekistan. The top three alternatives ranked by GRA were: Croatia, Cambodia, and Cabo. The top three alternatives ranked by Verde COPRAS were: the United States, Canada, and Switzerland.

Table 7. Results of proposed soft computation method and three other methods of comparison.

\begin{tabular}{|c|c|c|c|c|c|c|c|c|}
\hline \multirow{2}{*}{ TOP 10} & \multicolumn{2}{|c|}{ Modified VIKOR } & \multicolumn{2}{|c|}{ TOPSIS } & \multicolumn{2}{|r|}{ GRA } & \multicolumn{2}{|c|}{ COPRAS } \\
\hline & $R_{i}$ & Region/Country & $R_{i}$ & Region/Country & $R_{i}$ & Region/Country & $R_{i}$ & Region/Country \\
\hline 1 & 0.407 & Netherlands & 0.713 & Vanuatu & 0.818 & Croatia & 1.000 & United States \\
\hline 2 & 0.414 & Canada & 0.687 & Japan & 0.756 & Cambodia & 0.920 & Canada \\
\hline 3 & 0.442 & France & 0.670 & Uzbekistan & 0.732 & Cabo Verde & 0.864 & Switzerland \\
\hline 4 & 0.452 & Belgium & 0.642 & Grenada & 0.716 & Brazil & 0.860 & Thailand \\
\hline 5 & 0.461 & United Kingdom & 0.641 & Andorra & 0.715 & Australia & 0.847 & Denmark \\
\hline 6 & 0.464 & Thailand & 0.636 & Panama & 0.699 & Mauritius & 0.844 & Australia \\
\hline 7 & 0.464 & United States & 0.633 & Malaysia & 0.683 & Côte d'Ivoire & 0.839 & France \\
\hline 8 & 0.480 & Denmark & 0.611 & Belarus & 0.671 & Finland & 0.837 & Belgium \\
\hline 9 & 0.481 & Australia & 0.609 & Australia & 0.662 & Chin.a & 0.837 & Malaysia \\
\hline 10 & 0.484 & Slovenia & 0.604 & Marshall Islands & 0.657 & $\mathrm{CF}$ & 0.820 & Finland \\
\hline
\end{tabular}

In addition, in order to illustrate the differences between the methods, this study used Spearman's rank correlation coefficient to compare the relationship between the modified VIKOR method and other methods. The results are shown in Table 8 . The correlation coefficients between modified VIKOR and other methods were between -0.034 and 0.098 , but none of them reached the significant level. This means that the theoretical concept of the results obtained by the modified VIKOR method is different from other methods.

Table 8. Spearman's rank correlation coefficient of four methods.

\begin{tabular}{ccccc}
\hline Methods & Modified VIKOR & TOPSIS & GRA & COPRAS \\
\hline Modified VIKOR & 1.000 & 0.021 & 0.046 & 0.098 \\
TOPSIS & 0.021 & 1.000 & -0.034 & 0.059 \\
GRA & 0.046 & -0.034 & 1.000 & 0.042 \\
COPRAS & 0.098 & 0.059 & 0.042 & 1.000 \\
\hline
\end{tabular}

From this, it can be seen that the soft computation technique combined with the modified VIKOR enables the decision-making result to cover more decision information, and at the same time, it allows for the overall evaluation to be more objective and precise.

\section{Discussions}

\subsection{Management Implications}

In the previous section, we explained the core difference between the traditional and modified VIKOR methods. The modified VIKOR method, which is included in the proposed soft computation method, is superior because it not only preserves the original ranking function, but also allows for more complete and improved results. In the face of the rapid spread of COVID-19, achieving the goal of continued improvement of the healthcare system is one of the key factors for epidemic control. For this purpose, the proposed soft computation technique can be used to find the basis for improvement in the shortest time possible and provide more objective decision-making information to each region. Based on the weighted evaluation matrix (Table 9), we found that the Netherlands, the United States, and Slovenia had the smallest weighed gaps in the area of difficulty of adopting 
new technology $\left(D_{6}\right)$. Canada, France, and Belgium had the best performance in the area of interdisciplinary communication $\left(D_{4}\right)$.

Table 9. Performance evaluation of healthcare systems in various countries.

\begin{tabular}{ccccccccc}
\hline Code & Region/Country & Indicators & $\boldsymbol{D}_{\mathbf{1}}$ & $\boldsymbol{D}_{\mathbf{2}}$ & $\boldsymbol{D}_{\mathbf{3}}$ & $\boldsymbol{D}_{\mathbf{4}}$ & $\boldsymbol{D}_{\mathbf{5}}$ & $\boldsymbol{D}_{\mathbf{6}}$ \\
\hline \multirow{2}{*}{$A_{1}$} & \multirow{2}{*}{ Netherlands } & GAP & 0.042 & 0.054 & 0.004 & 0.127 & 0.088 & 0.000 \\
& & RANK & 3 & 4 & 2 & 6 & 5 & 1 \\
$A_{2}$ & Canada & GAP & 0.070 & 0.000 & 0.058 & 0.000 & 0.088 & 0.045 \\
& & RANK & 5 & 1 & 4 & 1 & 6 & 3 \\
$A_{3}$ & France & GAP & 0.059 & 0.054 & 0.056 & 0.000 & 0.088 & 0.090 \\
& & RANK & 4 & 2 & 3 & 1 & 5 & 6 \\
$A_{4}$ & Belgium & GAP & 0.059 & 0.054 & 0.058 & 0.000 & 0.088 & 0.090 \\
& United & RANK & 4 & 2 & 3 & 1 & 5 & 6 \\
$A_{5}$ & Kingdom & RANK & 0.050 & 0.054 & 0.057 & 0.127 & 0.088 & 0.000 \\
& & 2 & 3 & 4 & 6 & 5 & 1 \\
$A_{6}$ & Thailand & GAP & 0.064 & 0.108 & 0.001 & 0.000 & 0.088 & 0.000 \\
& & RANK & 4 & 6 & 3 & 1 & 5 & 1 \\
$A_{7}$ & United States & GAP & 0.049 & 0.054 & 0.078 & 0.000 & 0.000 & 0.000 \\
& & RANK & 4 & 5 & 6 & 1 & 1 & 1 \\
$A_{8}$ & Denmark & GAP & 0.040 & 0.108 & 0.058 & 0.000 & 0.088 & 0.000 \\
& & RANK & 3 & 6 & 4 & 1 & 5 & 1 \\
$A_{9}$ & Australia & GAP & 0.042 & 0.108 & 0.059 & 0.000 & 0.088 & 0.000 \\
& & RANK & 3 & 6 & 4 & 1 & 5 & 1 \\
$A_{10}$ & Slovenia & GAP & 0.066 & 0.054 & 0.055 & 0.127 & 0.088 & 0.045 \\
& & RANK & 4 & 2 & 3 & 6 & 5 & 1 \\
\hline
\end{tabular}

Thailand, Denmark, and Australia scored full marks for two indicators, namely interdisciplinary communication $\left(D_{4}\right)$ and difficulty of adopting new technology $\left(D_{6}\right)$. It is worth noting that the United States achieved a full score in three indicators, namely, interdisciplinary communication $\left(D_{4}\right)$, infection control $\left(D_{5}\right)$, and difficulty of adopting new technology $\left(D_{6}\right)$. This shows that in these three areas, the United States healthcare system is in the lead for future development. However, it should be noted that, faced with the COVID-19 outbreak, there is room for improvement in some areas in all these regions. This conclusion is in agreement with the GHS [20] report, which found that no country was adequately prepared for an outbreak or severe epidemic. All countries still have many aspects that require improvement.

To save space, we use only two examples for further explanation-the Netherlands and the United States. As shown in Figure 4, the Netherlands' gap to the aspiration level for most measures was larger than the United States. In theory then, the United States' performance should be better than the Netherlands', but the result of the evaluation was the opposite. From the original data, it can be seen that the Netherlands' and the United States' performance in healthcare accessibility were 95.7 and 25.3, respectively. Due to the difference in this one criterion, the final assessment result for the Netherlands was better than the United States. The proposed soft computing method can objectively determine the gap between the best case and the aspiration level. This breakthrough allows us to realize the desire of continued improvement in human development. Therefore, we use the Netherlands, which is one of the highest ranked regions in terms of overall healthcare system performance in the world, as an illustrative example. 


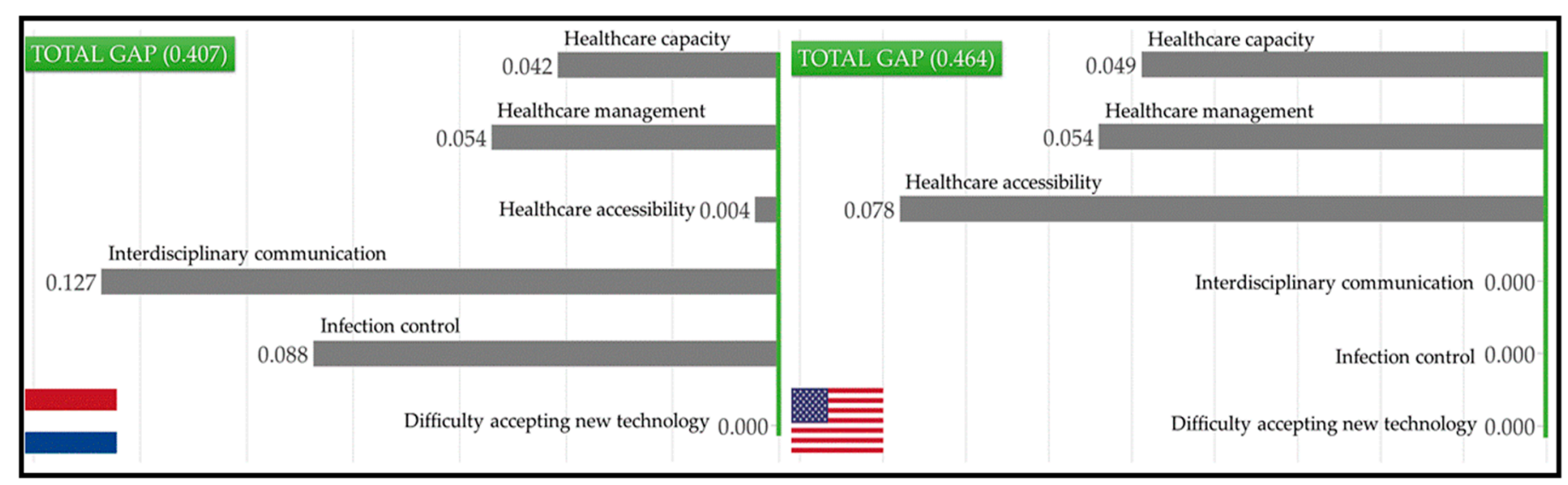

Figure 4. Healthcare system assessments in each region.

The left side of the Figure 4 shows that the Netherlands still has a total gap of 0.407 to the aspiration level. The weighted gaps of the six criteria obtained in this study are respectively as follows: interdisciplinary communication (0.127), infection control (0.088), healthcare management (0.054), healthcare capacity $(0.042)$, and healthcare accessibility (0.004).

Therefore, the order of improvement should be interdisciplinary communication, infection control, healthcare management, healthcare capacity, and healthcare accessibility. These six indicators are important points that the Netherlands should actively focus on, especially interdisciplinary communication. The analysis results show that the largest gap for the Netherlands is in the communication of healthcare workers in the event of public health emergency. Therefore, we suggest that during the COVID-19 epidemic, the national health authorities of the Netherlands should consider how the communication between healthcare workers can be improved. First, multiple channels should be used to spread the latest information. Second, depending on the state of the epidemic, they should prepare press releases or hold press conferences to explain the state of the epidemic and prevention measures. For the other case, we chose the United States, which already showed leading performance in three areas, but the region still has a total gap of 0.464 to the aspiration level. Although in the areas of interdisciplinary communication, infection control, and difficulty of adopting new technology, the United States showed excellent performance, in terms of healthcare accessibility, healthcare management, and healthcare capacity, there is still much room for improvement, especially healthcare accessibility. Therefore, it is suggested that healthcare management agencies in the United States should consider how to improve healthcare accessibility. For example, the establishment of special emergency clauses for the epidemic period, to protect front line healthcare workers and avoid paralysis of the healthcare system, as well as providing a larger healthcare budget to support medical insurance. Additionally, although the healthcare industry is highly developed, with robust infection prevention methods for clinical practices, it remains to be investigated whether the epidemic control in daily life settings reaches the same level.

\subsection{Theoretical Implications}

The core contribution of this research is to help national public health decision makers effectively and quickly discover the current problems facing the medical system, and provide decision makers with a direction for further improvement. In the face of the rapid changes in the medical system, this study combines two known methods, which not only quickly analyze, but also effectively reduce the technical threshold. For example, nowadays, Taiwan faces the invasion of unknown infectious diseases every day. The number of local confirmed cases is constantly appearing, which is a fatal challenge to the medical defense line. How to quickly find the gaps in the medical system and find 
the direction for improvement is one of the most important issue to fight the virus and strengthen the medical defense line.

Compromise solution VIKOR is suitable for multi-attribute decision-making problems. Multi-attribute evaluation systems often have a certain complexity, and there are conflicting and non-commensurable criteria between the evaluation criteria [51]. The national public health security system is a typical multi-attribute decision-making problem, so it is appropriate to use VIKOR method to evaluate the national public health security system. In addition, compared with the traditional compromise solution, the theoretical basis of VIKOR method considers the maximum "group utility" of the "majority" and the minimum of the "individual regret" of the "opponent" at the same time. This characteristic makes the results of decision analysis more secure [52]. However, the traditional VIKOR method has some problems when solving multiple criteria optimization problems [53]. The modified VIKOR introduces the concept of aspiration level, improves the traditional VIKOR method, and eliminates the problems that may occur in the traditional VIKOR method [54]. Therefore, the modified VIKOR is more novel and practical than the traditional VIKOR method. It is worth noting that in the multi-attribute decision-making problem, how to obtain the weight of the criteria is an important issue. In the past, many studies have combined VIKOR with AHP, ANP, DANP or other methods, and used these methods to obtain weights. However, these methods rely on experts' judgements to make decisions, and the results of decision-making are easily affected by the experience and preferences of experts [55].

Although the global health security (GHS) index has been proven to be an important evaluation indicator for controlling the spread of COVID-19, it still has similar problems with the above methods. The weight given by the index has been paid attention to and discussed by scholars [18]. Since the spread of the virus is global, if the decision-making process only considers the medical energy of a single region or country, such results may not be objective. CRITIC is a method of assigning relative weight to the importance of evaluation indicators based on the correlation between indicators. Many studies in the past have confirmed that CRITIC is an objective mathematical operation. Therefore, this study uses the CRITIC method to construct the weight of the global health security (GHS) index for 195 countries/regions around the world, which is a meaningful, convenient, and fast approach.

\section{Conclusions}

In this study, we discuss a method for the evaluation of a national healthcare system in the face of the global pandemic. This is key to epidemic prevention, creating a competitive advantage, and achieving sustainability on the national level. We propose a new type of soft computing technique. All of the data were retrieved from the international public database and mathematically calculated to acquire the weights of criteria. We then used a modified VIKOR method to find the gap to the aspiration level for each region, in order to avoid the limitations and disadvantages of the traditional methods. This computation technique can be used by countries to quickly assess their healthcare systems and obtain practical directions for improvement based on the gap to the aspiration level. In the case study, we used data from 195 regions around the world to prove the effectiveness of our model. From the results we can obtain the following findings. First, the three most important criteria for assessment of the national healthcare system during a global pandemic are interdisciplinary communication, difficulty of adopting new technology, and infection control. Second, faced with the serious COVID-19 epidemic, the healthcare systems of the Netherlands, Canada, France, Belgium, and the United Kingdom have shown superior performance. Third, the healthcare systems of all regions still have gaps that could be improved upon, and we must all work together for a common goal, to control the spread of the infection.

While this study is expected to make some contribution to national healthcare system evaluations, there are some suggestions for directions for future research. First, the frame- 
work for national healthcare system evaluation is quite varied when viewed from different angles; as such, conducting analysis with different assessment frameworks is a worthwhile subject of research. Various research institutes or organizations considered patient satisfaction as one of the criteria to assess the healthcare evaluation system. However, none of those could investigate this criterion worldwide. However, "patient satisfaction" is a useful instrument to value the healthcare process because it provides information about the perceived quality and, therefore, it can be incorporated in a program of valuation and quality improvement. The citizens' opinions offer the necessary information to adequately manage health resources. For this reason, patient satisfaction has been used to measure the performance of the NHS, since it is an excellent indicator of its quality and effectiveness. A high degree of patient satisfaction is usually linked to advanced compliance of the treatments. Thus, the issue of patient satisfaction should be addressed. Second, the opinions of healthcare experts from different countries could be gathered for analysis, and the results could be compared with existing studies. Third, our data were obtained by transforming quantitative data, so the measures have upper and lower bounds. However, in some cases, assessment criteria do not have upper or lower limits. It would be worth discussing how to set a suitable aspiration level in these situations. Finally, using the healthcare system as an example, different epidemic prevention systems could be compared with our model.

Author Contributions: S.-W.H. conducted the literature review, article writing, analyzed the data, and did formatting. H.-H.C. collected the data and did article writing. J.J.H.L. did writing-review and editing. Finally, G.-H.T. did writing-review. All authors have read and agreed to the published version of the manuscript.

Funding: This research was funded by the Ministry of Science and Technology, Taiwan, grant number MOST 107-2410-H-305-038-MY3, MOST 108-2221-E-305-002-MY3 and MOST 109-2410-H-305-056.

Institutional Review Board Statement: Not applicable.

Informed Consent Statement: Not applicable.

Data Availability Statement: No new data were created or analyzed in this study. Data sharing is not applicable to this article.

Conflicts of Interest: The authors declare no conflict of interest.

\section{Appendix A}

Use the proposed soft computing technology for global ranking. The evaluation results are shown in Tables A1 and A2.

Table A1. Performance evaluation of healthcare systems in various countries.

\begin{tabular}{|c|c|c|c|c|c|c|c|c|}
\hline NO & Region/Country & $R_{i}$ & & Region/Country & $R_{i}$ & & Region/Country & $R_{i}$ \\
\hline 1 & Netherlands & 0.407 & 41 & Saudi Arabia & 0.798 & 81 & Montenegro & 0.871 \\
\hline 2 & Canada & 0.414 & 42 & Singapore & 0.805 & 82 & Brunei & 0.873 \\
\hline 3 & France & 0.442 & 43 & Israel & 0.807 & 83 & Bhutan & 0.873 \\
\hline 4 & Belgium & 0.452 & 44 & Bulgaria & 0.807 & 84 & Armenia & 0.875 \\
\hline 5 & $\begin{array}{l}\text { United } \\
\text { Kingdom }\end{array}$ & 0.461 & 45 & Ireland & 0.808 & 85 & Kazakhstan & 0.877 \\
\hline 6 & Thailand & 0.464 & 46 & Nepal & 0.812 & 86 & El Salvador & 0.880 \\
\hline 7 & United States & 0.464 & 47 & Czech Republic & 0.820 & 87 & Ghana & 0.881 \\
\hline 8 & Denmark & 0.480 & 48 & Belarus & 0.821 & 88 & $\begin{array}{c}\text { North } \\
\text { Macedonia }\end{array}$ & 0.881 \\
\hline 9 & Australia & 0.481 & 49 & Philippines & 0.821 & 89 & Costa Rica & 0.884 \\
\hline 10 & Slovenia & 0.484 & 50 & Romania & 0.823 & 90 & Uruguay & 0.884 \\
\hline 11 & South Korea & 0.485 & 51 & Iran & 0.827 & 91 & Gambia & 0.886 \\
\hline 12 & Argentina & 0.487 & 52 & Qatar & 0.827 & 92 & Oman & 0.886 \\
\hline 13 & Switzerland & 0.488 & 53 & Luxembourg & 0.830 & 93 & Myanmar & 0.889 \\
\hline 14 & Spain & 0.495 & 54 & Slovakia & 0.830 & 94 & Lebanon & 0.889 \\
\hline
\end{tabular}


Table A1. Cont.

\begin{tabular}{|c|c|c|c|c|c|c|c|c|}
\hline NO & Region/Country & $R_{i}$ & & Region/Country & $R_{i}$ & & Region/Country & $R_{i}$ \\
\hline 15 & Finland & 0.502 & 55 & Greece & 0.831 & 95 & Ukraine & 0.890 \\
\hline 16 & Norway & 0.511 & 56 & Russia & 0.831 & 96 & Rwanda & 0.890 \\
\hline 17 & Malaysia & 0.548 & 57 & Colombia & 0.832 & 97 & Pakistan & 0.891 \\
\hline 18 & Latvia & 0.584 & 58 & Italy & 0.834 & 98 & Liberia & 0.891 \\
\hline 19 & Poland & 0.591 & 59 & Hungary & 0.835 & 99 & Malta & 0.891 \\
\hline 20 & Serbia & 0.599 & 60 & Kuwait & 0.835 & 100 & Cyprus & 0.895 \\
\hline 21 & Iceland & 0.599 & 61 & Moldova & 0.836 & 101 & Senegal & 0.896 \\
\hline 22 & Mexico & 0.600 & 62 & Panama & 0.838 & 102 & $\mathrm{TT}$ & 0.897 \\
\hline 23 & Nicaragua & 0.601 & 63 & Georgia & 0.839 & 103 & Niger & 0.897 \\
\hline 24 & Turkey & 0.708 & 64 & Ecuador & 0.839 & 104 & Cameroon & 0.897 \\
\hline 25 & Peru & 0.733 & 65 & Lithuania & 0.842 & 105 & Kenya & 0.897 \\
\hline 26 & India & 0.750 & 66 & Sierra Leone & 0.845 & 106 & Tajikistan & 0.901 \\
\hline 27 & Portugal & 0.757 & 67 & Ethiopia & 0.846 & 107 & Zambia & 0.901 \\
\hline 28 & Sweden & 0.759 & 68 & South Africa & 0.847 & 108 & SVG & 0.905 \\
\hline 29 & New Zealand & 0.763 & 69 & Liechtenstein & 0.850 & 109 & Azerbaijan & 0.905 \\
\hline 30 & Chile & 0.775 & 70 & Estonia & 0.852 & 110 & UAE & 0.906 \\
\hline 31 & Austria & 0.776 & 71 & Mongolia & 0.853 & 111 & Madagascar & 0.907 \\
\hline 32 & Japan & 0.776 & 72 & Morocco & 0.857 & 112 & Afghanistan & 0.907 \\
\hline 33 & China & 0.778 & 73 & Monaco & 0.860 & 113 & Lesotho & 0.912 \\
\hline 34 & Albania & 0.778 & 74 & Paraguay & 0.860 & 114 & Mauritania & 0.913 \\
\hline 35 & Brazil & 0.782 & 75 & Tunisia & 0.863 & 115 & Nigeria & 0.916 \\
\hline 36 & Cuba & 0.782 & 76 & Bahrain & 0.864 & 116 & Seychelles & 0.917 \\
\hline 37 & Germany & 0.786 & 77 & Syria & 0.865 & 117 & Laos & 0.917 \\
\hline 38 & $\begin{array}{l}\text { Bosnia and } \\
\text { Herzegovina }\end{array}$ & 0.791 & 78 & $\begin{array}{l}\text { Kyrgyz } \\
\text { Republic }\end{array}$ & 0.871 & 118 & Maldives & 0.921 \\
\hline 39 & Croatia & 0.793 & 79 & Jordan & 0.871 & 119 & Mozambique & 0.922 \\
\hline 40 & Indonesia & 0.795 & 80 & Vietnam & 0.871 & 120 & Micronesia & 0.923 \\
\hline
\end{tabular}

Table A2. Using soft computing to rank (other).

\begin{tabular}{|c|c|c|c|c|c|}
\hline NO & Region/Country & $R_{i}$ & NO & Region/Country & $R_{i}$ \\
\hline 121 & Sri Lanka & 0.923 & 159 & Djibouti & 0.959 \\
\hline 122 & $\begin{array}{c}\text { Central African } \\
\text { Republic }\end{array}$ & 0.924 & 160 & Samoa & 0.960 \\
\hline 123 & Uzbekistan & 0.924 & 161 & Togo & 0.960 \\
\hline 124 & Suriname & 0.924 & 162 & Burundi & 0.961 \\
\hline 125 & Cabo Verde & 0.926 & 163 & Eritrea & 0.961 \\
\hline 126 & $\begin{array}{l}\text { Dominican } \\
\text { Republic }\end{array}$ & 0.926 & 164 & North Korea & 0.961 \\
\hline 127 & Côte d'Ivoire & 0.926 & 165 & Nauru & 0.962 \\
\hline 128 & Malawi & 0.927 & 166 & Tanzania & 0.963 \\
\hline 129 & Egypt & 0.927 & 167 & Yemen & 0.964 \\
\hline 130 & Zimbabwe & 0.933 & 168 & Palau & 0.965 \\
\hline 131 & Botswana & 0.934 & 169 & Gabon & 0.966 \\
\hline 132 & Sudan & 0.934 & 170 & Grenada & 0.967 \\
\hline 133 & San Marino & 0.937 & 171 & Chad & 0.967 \\
\hline 134 & Guyana & 0.937 & 172 & Belize & 0.970 \\
\hline 135 & Mali & 0.938 & 173 & Timor-Leste & 0.971 \\
\hline 136 & Mauritius & 0.939 & 174 & Andorra & 0.972 \\
\hline 137 & Uganda & 0.939 & 175 & Niue & 0.972 \\
\hline 138 & Cook Islands & 0.942 & 176 & Barbados & 0.974 \\
\hline 139 & Bangladesh & 0.944 & 177 & Dominica & 0.974 \\
\hline 140 & Turkmenistan & 0.945 & 178 & Bahamas & 0.976 \\
\hline
\end{tabular}


Table A2. Cont.

\begin{tabular}{|c|c|c|c|c|c|}
\hline NO & Region/Country & $R_{i}$ & NO & Region/Country & $R_{i}$ \\
\hline 141 & Bolivia & 0.946 & 179 & Guinea & 0.977 \\
\hline 142 & South Sudan & 0.947 & 180 & Tonga & 0.978 \\
\hline 143 & Algeria & 0.948 & 181 & Fiji & 0.978 \\
\hline 144 & Solomon Islands & 0.949 & 182 & $\begin{array}{l}\text { Antigua and } \\
\text { Barbuda }\end{array}$ & 0.978 \\
\hline 145 & Venezuela & 0.949 & 183 & Kiribati & 0.978 \\
\hline 146 & Cambodia & 0.950 & 184 & $\begin{array}{l}\text { St Kitts and } \\
\text { Nevis }\end{array}$ & 0.978 \\
\hline 147 & Tuvalu & 0.950 & 185 & $\begin{array}{c}\text { São Tomé and } \\
\text { Príncipe }\end{array}$ & 0.979 \\
\hline 148 & Congo & 0.950 & 186 & Marshall Islands & 0.979 \\
\hline 149 & $\begin{array}{l}\text { Papua New } \\
\text { Guinea }\end{array}$ & 0.951 & 187 & Vanuatu & 0.981 \\
\hline 150 & Honduras & 0.952 & 188 & $\begin{array}{c}\text { eSwatini } \\
\text { (Swaziland) }\end{array}$ & 0.981 \\
\hline 151 & Iraq & 0.952 & 189 & St Lucia & 0.982 \\
\hline 152 & Guatemala & 0.953 & 190 & $\begin{array}{c}\text { Congo } \\
\text { (Brazzaville) }\end{array}$ & 0.982 \\
\hline 153 & Angola & 0.955 & 192 & Burkina Faso & 0.984 \\
\hline 154 & Haiti & 0.956 & 191 & Benin & 0.983 \\
\hline 155 & Namibia & 0.957 & 193 & $\begin{array}{c}\text { Equatorial } \\
\text { Guinea }\end{array}$ & 0.985 \\
\hline 156 & Jamaica & 0.957 & 194 & Guinea-Bissau & 0.987 \\
\hline 157 & Libya & 0.958 & 195 & Somalia & 0.999 \\
\hline 158 & Comoros & 0.959 & & The end & \\
\hline
\end{tabular}

\section{References}

1. Fernandes, N. Economic Effects of Coronavirus Outbreak (COVID-19) on the World Economy; IESE Business School Working Paper No. WP-1240-E; IESE Business School: Barcelona, Spain, 2020.

2. Ren, J.L.; Zhang, A.H.; Wang, X.J. Traditional Chinese medicine for COVID-19 treatment. Pharmacol. Res. 2020, 155, 104743. [CrossRef]

3. Roback, J.D.; Guarner, J. Convalescent plasma to treat COVID-19: Possibilities and challenges. JAMA 2020, 323, 1561-1562. [CrossRef] [PubMed]

4. Shet, A.; Ray, D.; Malavige, N.; Santosham, M.; Bar-Zeev, N. Differential COVID-19-attributable mortality and BCG vaccine use in countries. medRxiv 2020. [CrossRef]

5. Hellewell, J.; Abbott, S.; Gimma, A.; Bosse, N.I.; Jarvis, C.I.; Russell, T.W.; Munday, J.D.; Kucharski, A.J.; Edmunds, W.J.; Centre for the Mathematical Modelling of Infectious Diseases COVID-19 Working Group; et al. Feasibility of controlling COVID-19 outbreaks by isolation of cases and contacts. Lancet Glob. Health 2020, 8, 488-496. [CrossRef]

6. Williams, S.N.; Armitage, C.J.; Tampe, T.; Dienes, K. Public perceptions and experiences of social distancing and social iso-lation during the COVID-19 pandemic: A UK-based focus group study. BMJ Open 2020, 10, 1-8. [CrossRef] [PubMed]

7. Anderson, R.M.; Heesterbeek, H.; Klinkenberg, D.; Hollingsworth, T.D. How will country-based mitigation measures in-fluence the course of the COVID-19 epidemic? Lancet 2020, 395, 931-934. [CrossRef]

8. Requia, W.J.; Kondo, E.K.; Adams, M.D.; Gold, D.R.; Struchiner, C.J. Risk of the Brazilian health care system over 5572 municipalities to exceed health care capacity due to the 2019 novel coronavirus (COVID-19). Sci. Total Environ. 2020, 730, 139144. [CrossRef]

9. Rogers, L.C.; Lavery, L.A.; Joseph, W.S.; Armstrong, D.G. All Feet on Deck-The Role of Podiatry during the COVID-19 Pandemic: Preventing hospitalizations in an overburdened healthcare system, reducing amputation and death in people with diabetes. J. Am. Podiatr. Med. Assoc. 2020, 1-11. [CrossRef]

10. Jefferson. COVID-19: Spread the Science, Not the Virus. Available online: https://u.nu/yzj9y (accessed on 22 April 2019).

11. WHO. The World Health Report 2000. Health Systems: Improving Performance, 1st ed.; World Health Organization: Geneva, Switzerland, 2000.

12. Top, M.; Konca, M.; Sapaz, B. Technical efficiency of healthcare systems in African countries: An application based on data envelopment analysis. Health Policy Technol. 2020, 9, 62-68. [CrossRef]

13. Yanyan, W. Improving the Healthcare Service Quality in Chinese Public Class-A Hospitals: From Frontline Healthcare ProfesSional's Perspectives. Master's Thesis, ISCTE-University Institute of Lisbon, Lisbon, Portugal, 2018. 
14. Marzban, S.; Daneshkohan, A.; Najafi, M. Study of some of quality process indicators of hospital emergency services for Victims of traffic accidents in Imam Khomeini hospital. J. Inj. Violence Res. 2019, 11, 153. [CrossRef]

15. Biancone, P.P.; Secinaro, S.; Brescia, V. Better Life Index and Health Care Quality Indicators, Two New Instruments to Evaluate the Healthcare System. Int. J. Bus. Manag. 2018, 13, 29. [CrossRef]

16. Eriksson, C.O.; Stoner, R.C.; Eden, K.B.; Newgard, C.D.; Guise, J.-M. The Association between Hospital Capacity Strain and Inpatient Outcomes in Highly Developed Countries: A Systematic Review. J. Gen. Intern. Med. 2017, 32, 686-696. [CrossRef] [PubMed]

17. Verelst, F.; Kuylen, E.; Beutels, P. Indications for healthcare surge capacity in European countries facing an exponential in-crease in coronavirus disease (COVID-19) cases, March 2020. Eurosurveillance 2020, 25, 2000323. [CrossRef] [PubMed]

18. Razavi, A.; Erondu, N.A.; Okereke, E. The Global Health Security Index: What value does it add? BMJ Glob. Health 2020, 5, e002477. [CrossRef]

19. SSRN. Is the Global Health Security (GHS) Index a Significant Factor Associated with COVID-19 Control? A Country Level Analysis. Available online: https:/ / papers.ssrn.com/sol3/papers.cfm?abstract_id=3582746 (accessed on 13 April 2020).

20. GHS Index Report. Available online: https://www.ghsindex.org/wp-content/uploads/2019/10/2019-Global-Health-SecurityIndex.pdf (accessed on 26 September 2020).

21. Diakoulaki, D.; Mavrotas, G.; Papayannakis, L. Determining objective weights in multiple criteria problems: The critic method. Comput. Oper. Res. 1995, 22, 763-770. [CrossRef]

22. Yalçin, N.; Ünlü, U. A Multi-Criteria Performance Analysis of Initial Public Offering (IPO) Firms Using Critic and Vikor Methods. Technol. Econ. Dev. Econ. 2017, 24, 534-560. [CrossRef]

23. Liou, J.J.H. New Concepts and Trends of MCDM for Tomorrow-In Honor of Professor Gwo-Hshiung Tzeng on the Occasion of His 70th Birthday. Technol. Econ. Dev. Econ. 2013, 19, 367-375. [CrossRef]

24. Tzeng, G.-H.; Shen, K.-Y. New Concepts and Trends of Hybrid Multiple Criteria Decision Making; CRC Press: Boca Raton, FL, USA, 2017.

25. Budiwan, V. Efendi The Understanding of Indonesian Patients of Hospital Service Quality in Singapore. Procedia Soc. Behav. Sci. 2016, 224, 176-183. [CrossRef]

26. Karltun, A.; Sanne, J.M.; Aase, K.; Anderson, J.E.; Fernandes, A.; Fulop, N.J.; Höglund, P.J.; Gare, B.A. Knowledge man-agement infrastructure to support quality improvement: A qualitative study of maternity services in four European hospitals. Health Policy 2020, 124, 205-215. [CrossRef]

27. Meesala, A.; Paul, J. Service quality, consumer satisfaction and loyalty in hospitals: Thinking for the future. J. Retail. Consum. Serv. 2018, 40, 261-269. [CrossRef]

28. Zawisza, K.; Galas, A.; Tobiasz-Adamczyk, B. Factors associated with patient satisfaction with health care among Polish older people: Results from the polish part of the COURAGE in Europe. Public Health 2020, 179, 169-177. [CrossRef]

29. Martínez, M.D.C.V.; Ramírez-Orellana, A. Patient Satisfaction in the Spanish National Health Service: Partial Least Squares Structural Equation Modeling. Int. J. Environ. Res. Public Health 2019, 16, 4886. [CrossRef] [PubMed]

30. Martínez, M.V.; Ramírez-Orellana, A.; Grasso, M. Health Investment Management and Healthcare Quality in the Public System: A Gender Perspective. Int. J. Environ. Res. Public Health 2021, 18, 2304. [CrossRef] [PubMed]

31. Kidwai, B.; Nadesh, R.K. Design and development of diagnostic Chabot for supporting primary health care systems. Procedia Computer. Sci. 2020, 167, 75-84. [CrossRef]

32. Chen, M.; Li, W.; Hao, Y.; Qian, Y.; Humar, I. Edge cognitive computing based smart healthcare system. Futur. Gener. Comput. Syst. 2018, 86, 403-411. [CrossRef]

33. Hejazi, T.H.; Badri, H.; Yang, K. A Reliability-based Approach for Performance Optimization of Service Industries: An Application to Healthcare Systems. Eur. J. Oper. Res. 2019, 273, 1016-1025. [CrossRef]

34. Teymourifar, A.; Kaya, O.; Ozturk, G. Contracting models for pricing and capacity decisions in healthcare systems. Omega 2020, 100, 102232. [CrossRef]

35. Yaya, S.; Xi, C.; Xiaoyang, Z.; Meixia, Z. Evaluating the efficiency of China's healthcare service: A weighted DEA-game theory in a competitive environment. J. Clean. Prod. 2020, 270, 122431. [CrossRef]

36. Mardani, A.; Hooker, R.E.; Ozkul, S.; Yifan, S.; Nilashi, M.; Sabzi, H.Z.; Fei, G.C. Application of decision making and fuzzy sets theory to evaluate the healthcare and medical problems: A review of three decades of research with recent developments. Expert Syst. Appl. 2019, 137, 202-231. [CrossRef]

37. La Fata, C.M.; Lupo, T.; Piazza, T. Service quality benchmarking via a novel approach based on fuzzy ELECTRE III and IPA: An empirical case involving the Italian public healthcare context. Health Care Manag. Sci. 2017, 22, 106-120. [CrossRef]

38. Bahadori, M.; Teymourzadeh, E.; Faizy Bagejan, F.; Ravangard, R.; Raadabadi, M.; Hosseini, S.M. Factors affecting the effectiveness of quality control circles in a hospital using a combination of fuzzy VIKOR and Grey Relational Analysis. Proc. Singap. Healthc. 2018, 27, 180-186. [CrossRef]

39. Otay, İ.; Oztaysi, B.; Onar, S.C.; Kahraman, C. Multi-expert performance evaluation of healthcare institutions using an in-tegrated intuitionistic fuzzy AHP\&DEA methodology. Knowl. Based Syst. 2017, 133, 90-106.

40. Haghighi, S.M.; Torabi, S.A. A novel mixed sustainability-resilience framework for evaluating hospital information systems. Int. J. Med. Inform. 2018, 118, 16-28. [CrossRef] 
41. Si, S.-L.; You, X.-Y.; Liu, H.-C.; Huang, J. Identifying Key Performance Indicators for Holistic Hospital Management with a Modified DEMATEL Approach. Int. J. Environ. Res. Public Health 2017, 14, 934. [CrossRef]

42. Gul, M.; Celik, E.; Gumus, A.T.; Guneri, A.F. Emergency department performance evaluation by an integrated simulation and interval type-2 fuzzy MCDM-based scenario analysis. Eur. J. Ind. Eng. 2016, 10, 196. [CrossRef]

43. Amiri, M.; Hashemi-Tabatabaei, M.; Ghahremanloo, M.; Keshavarz-Ghorabaee, M.; Zavadskas, E.K.; Antucheviciene, J. A new fuzzy approach based on BWM and fuzzy preference programming for hospital performance evaluation: A case study. Appl. Soft Comput. 2020, 92, 106279. [CrossRef]

44. Tuzkaya, G.; Sennaroglu, B.; Kalender, Z.T.; Mutlu, M. Hospital service quality evaluation with IVIF-PROMETHEE and a case study. Socio Econ. Plan. Sci. 2019, 68, 100705. [CrossRef]

45. Chang, T.-H. Fuzzy VIKOR method: A case study of the hospital service evaluation in Taiwan. Inf. Sci. 2014, 271 , 196-212. [CrossRef]

46. Baki, B.; Peker, I. An Integrated Evaluation Model for Service Quality of Hospitals: A Case Study from Turkey. J. Mult. Valued Log. $S$ 2015, 24, 453-474.

47. Sinimole, K.R. Performance evaluation of the hospital services-a fuzzy analytic hierarchy process model. Int. J. Product Q 2012, 10, 112-130. [CrossRef]

48. Büyüközkan, G.; Çifçi, G.; Güleryüz, S. Strategic analysis of healthcare service quality using fuzzy AHP methodology. Expert Syst. Appl. 2011, 38, 9407-9424. [CrossRef]

49. Tsai, H.Y.; Chang, C.W.; Lin, H.L. Fuzzy hierarchy sensitive with Delphi method to evaluate hospital organization per-formance. Expert Syst. Appl. 2010, 37, 5533-5541. [CrossRef]

50. GHS Index. Available online: https:/ / www.ghsindex.org/wp-content/uploads/2019/10/Global-Health-Security-Index-2019 -Final-October-2019.zip (accessed on 26 September 2020).

51. Opricovic, S.; Tzeng, G.-H. Extended VIKOR method in comparison with outranking methods. Eur. J. Oper. Res. 2007, 178, 514-529. [CrossRef]

52. Tzeng, G.H.; Huang, J.J. Multiple Attribute Decision Making: Methods and Applications, 1st ed.; CRC Press: London, UK, 2011.

53. Chang, C.-L. A modified VIKOR method for multiple criteria analysis. Environ. Monit. Assess. 2009, 168, 339-344. [CrossRef] [PubMed]

54. Liou, J.J.; Tsai, C.-Y.; Lin, R.-H.; Tzeng, G.-H. A modified VIKOR multiple-criteria decision method for improving domestic airlines service quality. J. Air Transp. Manag. 2011, 17, 57-61. [CrossRef]

55. Huang, S.-W.; Liou, J.J.; Tang, W.; Tzeng, G.-H. Location Selection of a Manufacturing Facility from the Perspective of Supply Chain Sustainability. Symmetry 2020, 12, 1418. [CrossRef] 